\title{
NEUROLOGÍA. EL DÍA QUE NIETZSCHE LLORÓ (2007). FRIEDRICH NIETZSCHE: UNA APROXIMACIÓN CINEMATOGRÁFICA
}

Neurology. When Nietzsche Wept (2007). Friedrich Nietzsche: A cinematographic approach

Samanta PICÓN; Ivan ANDÍA-RODRÍGUEZ

${ }^{1}$ Universidad Privada Norbert Wiener. Facultad de Medicina Humana. Lima (Perú).

Autor para correspondencia: Ivan Emerson Andía Rodriguez

Correo electrónico: ivanemerson01@gmail.com samantapiconflores@gmail.com

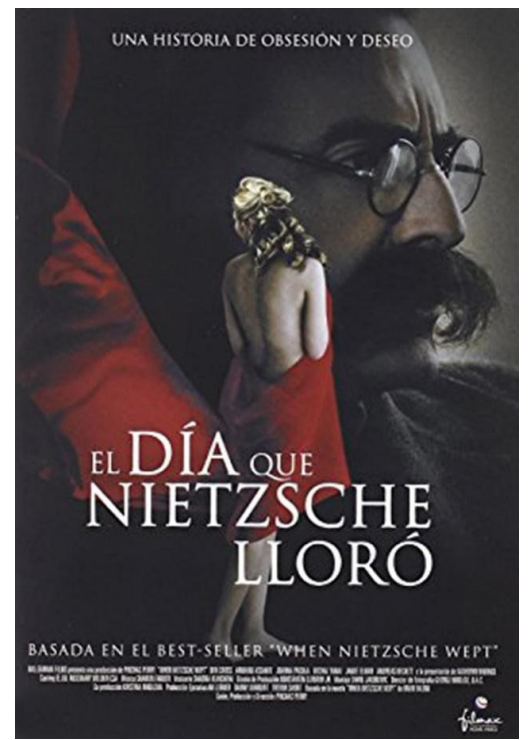

Drama: Ambientada en Viena de 1882 Cartel español.
Ficha Técnica

Título Original: When Nietzsche Wept País: Estados Unidos.

Año: 2007.

Director: Pinchas Perry.

Producción: Pinchas Perry.

Música: Sharon Farber.

Fotografía: Georgi Nikolov.

Montaje: David Jakubovic.

Guión: Pinchas Perry.

Intérpretes: Armand Assante (Como Nietzsche), Ben Cross (Como Josef Breuer), Katheryn Winnick (Como Lou Salome), Jamie Elman, Joanna, Pacula, Michal Yannai, ...

Color: color.

Duración: 105 minutos.

Género: drama, biográfico. 
NEUROLOGÍA. EL DÍA QUE NIETZSCHE LLORÓ (2007).

FRIEDRICH NIETZSCHE: UNA APROXIMACIÓN CINEMATOGRÁFICA

SAMANTA PICÓN; IVAN ANDÍA-RODRÍGUEZ

Idioma Original: inglés.

Productoras: Millennium Films.

Sinopsis: «El doctor vienés Josef Breuer se reúne con el filósofo Friedrich Nietzsche para ayudarle a superar su desesperanza» (FilmAffinity).
Enlaces: https://www.imdb.com/title/ tt0760188/?ref_=nv_sr_srsg_0 https://www.filmaffinity.com/pe/film721567. html

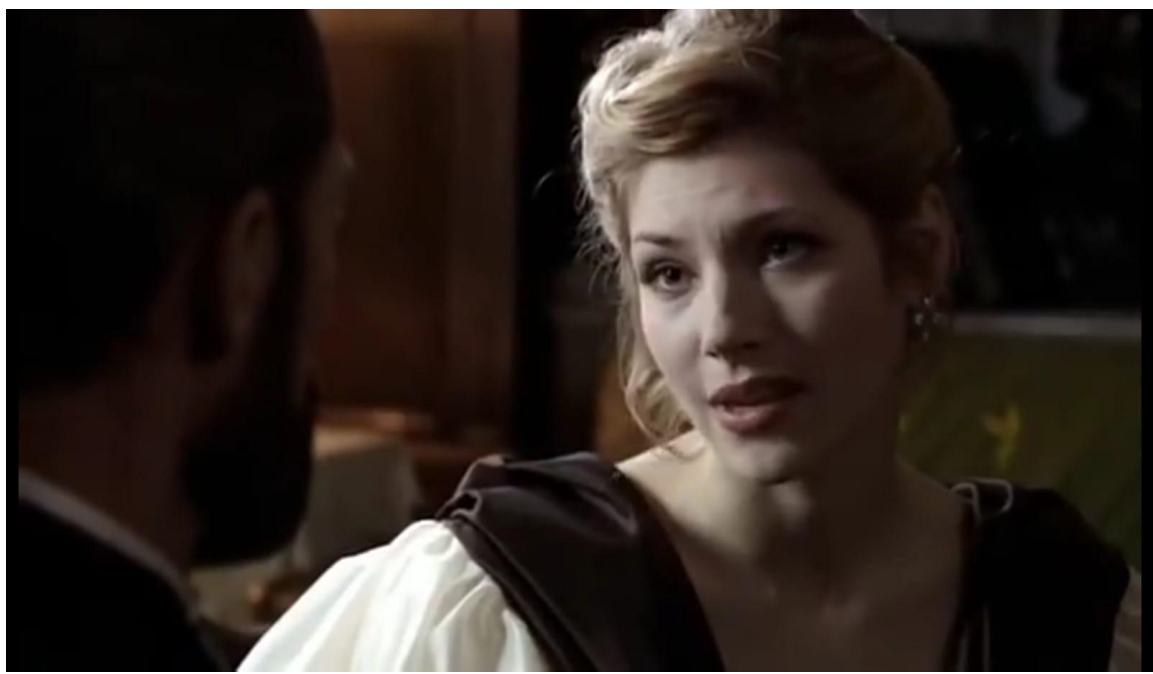

Lou Salome acude al consultorio del Dr. Breuer en busca de terapia para Friedrich Nietzsche. 00:07:48

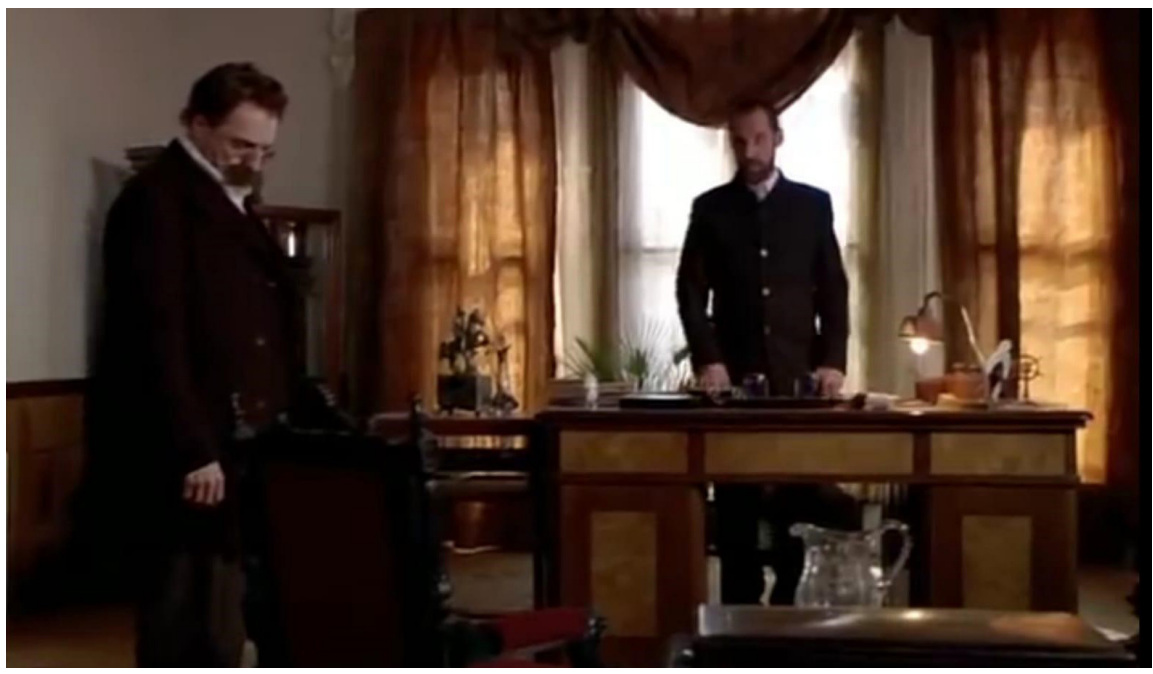

Nietzsche acepta acudir al llamado del Dr. Breuer, sin esperanza de mejora. 00:12:02

Rev. Med. Cine. 2021; 17 (2), 161-169 Ediciones Universidad de Salamanca /

(요요

J. Med. Mov., 2021; 17 (2), 161-169 [ 162 ] 
NEUROLOGÍA. EL DÍA QUE NIETZSCHE LLORÓ (2007).

FRIEDRICH NIETZSCHE: UNA APROXIMACIÓN CINEMATOGRÁFICA

SAMANTA PICÓN; IVAN ANDÍA-RODRÍGUEZ

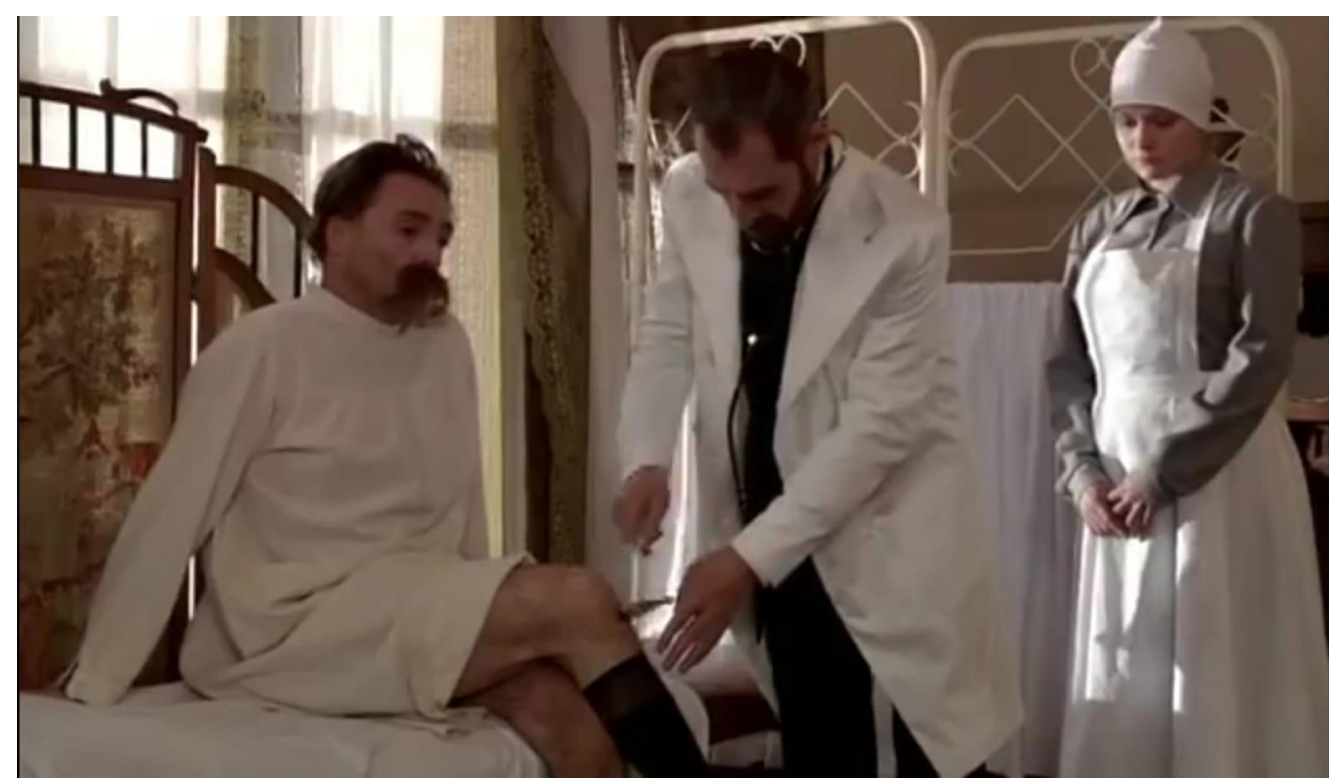

Evaluación de reflejos osteo-tendinosos. 00:12:43

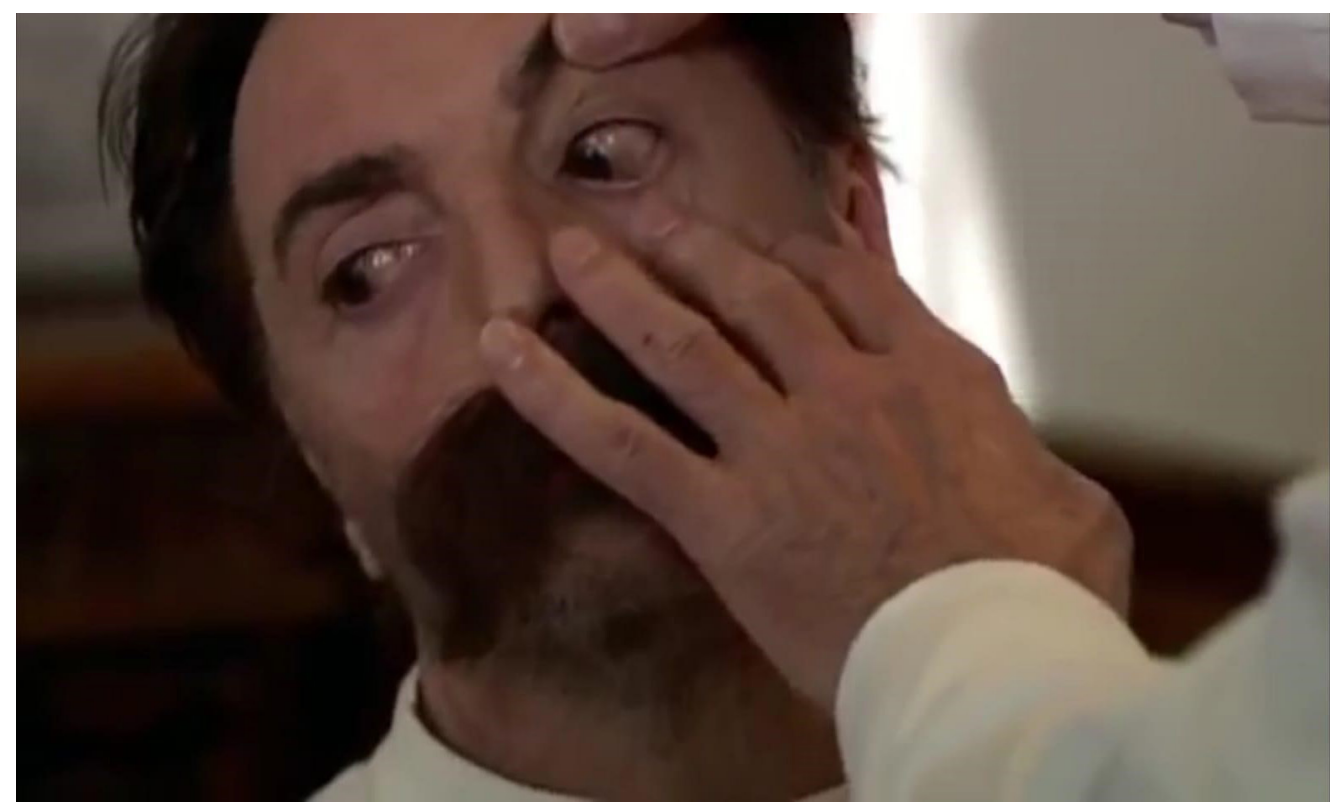

Exploración de escleras. 00:12:46

Rev. Med. Cine. 2021; 17 (2), 161-169 Ediciones Universidad de Salamanca / @@ J. Med. Mov., 2021; 17 (2), 161-169 [ 163 ] 
NEUROLOGÍA. EL DÍA QUE NIETZSCHE LLORÓ (2007).

FRIEDRICH NIETZSCHE: UNA APROXIMACIÓN CINEMATOGRÁFICA

SAMANTA PICÓN; IVAN ANDÍA-RODRÍGUEZ

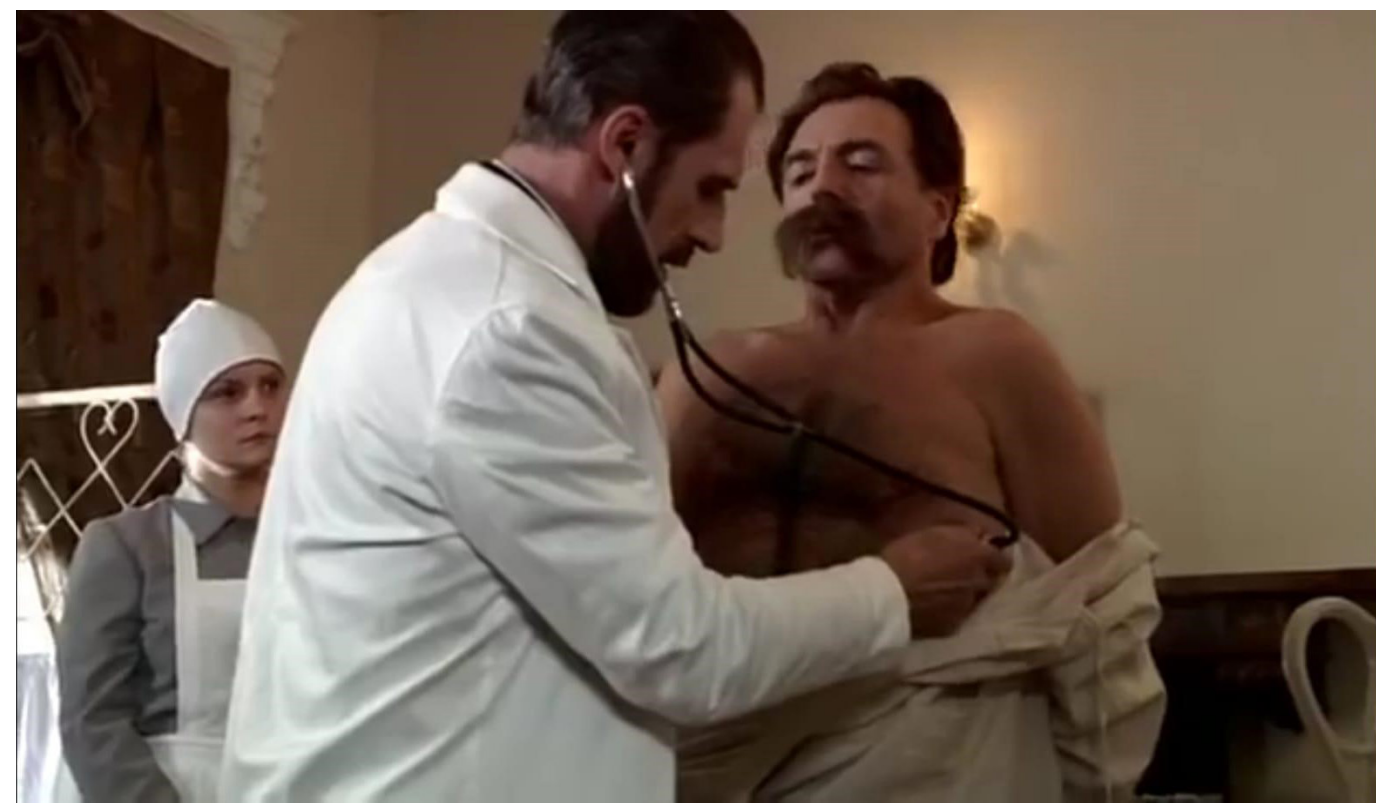

Auscultación cardio-pulmonar. 00:12:52

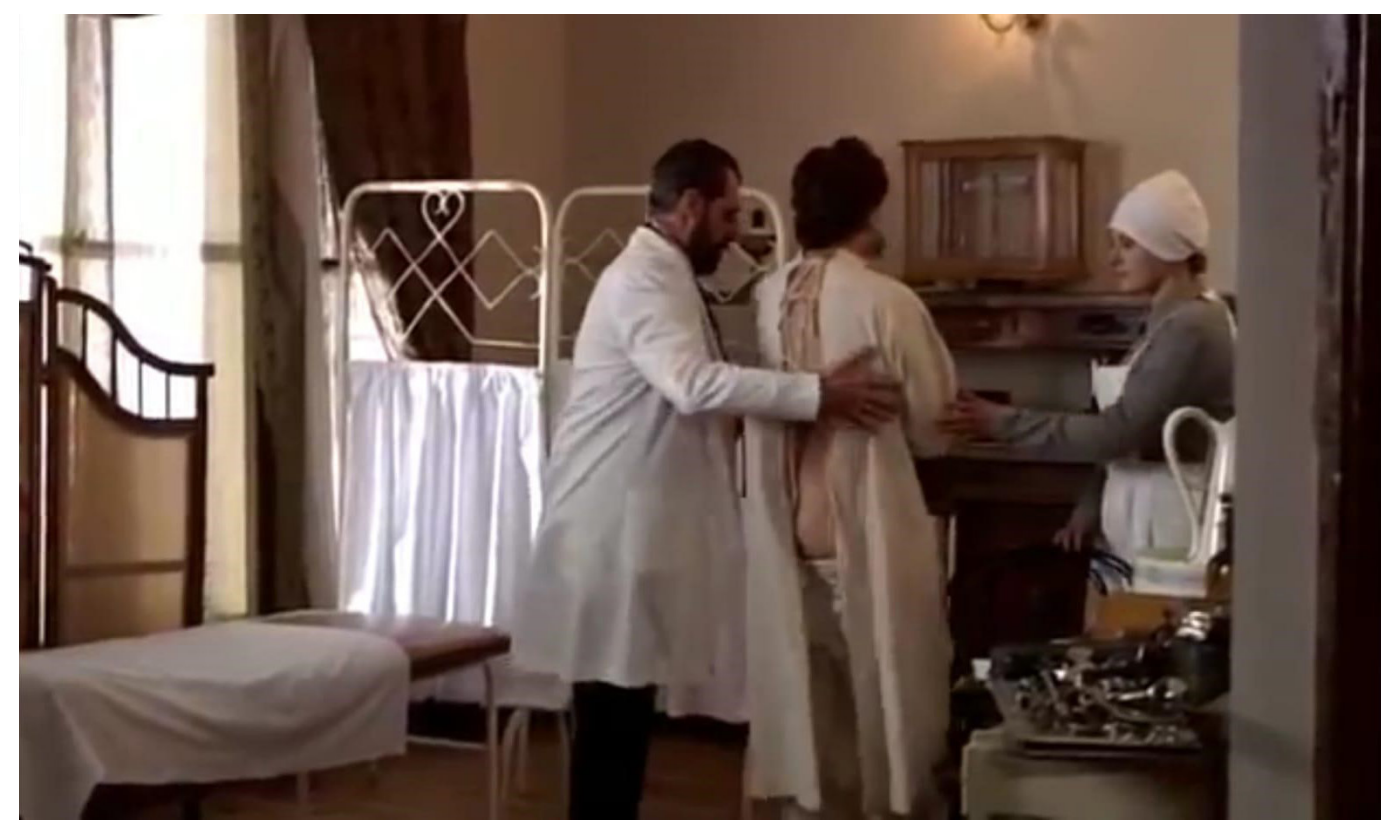

Evaluación de la marcha. 00:12:57

Rev. Med. Cine. 2021; 17 (2), 161-169 Ediciones Universidad de Salamanca / @@@

J. Med. Mov., 2021; 17 (2), 161-169 [ 164 ] 
NEUROLOGÍA. EL DÍA QUE NIETZSCHE LLORÓ (2007).

FRIEDRICH NIETZSCHE: UNA APROXIMACIÓN CINEMATOGRÁFICA

SAMANTA PICÓN; IVAN ANDÍA-RODRÍGUEZ

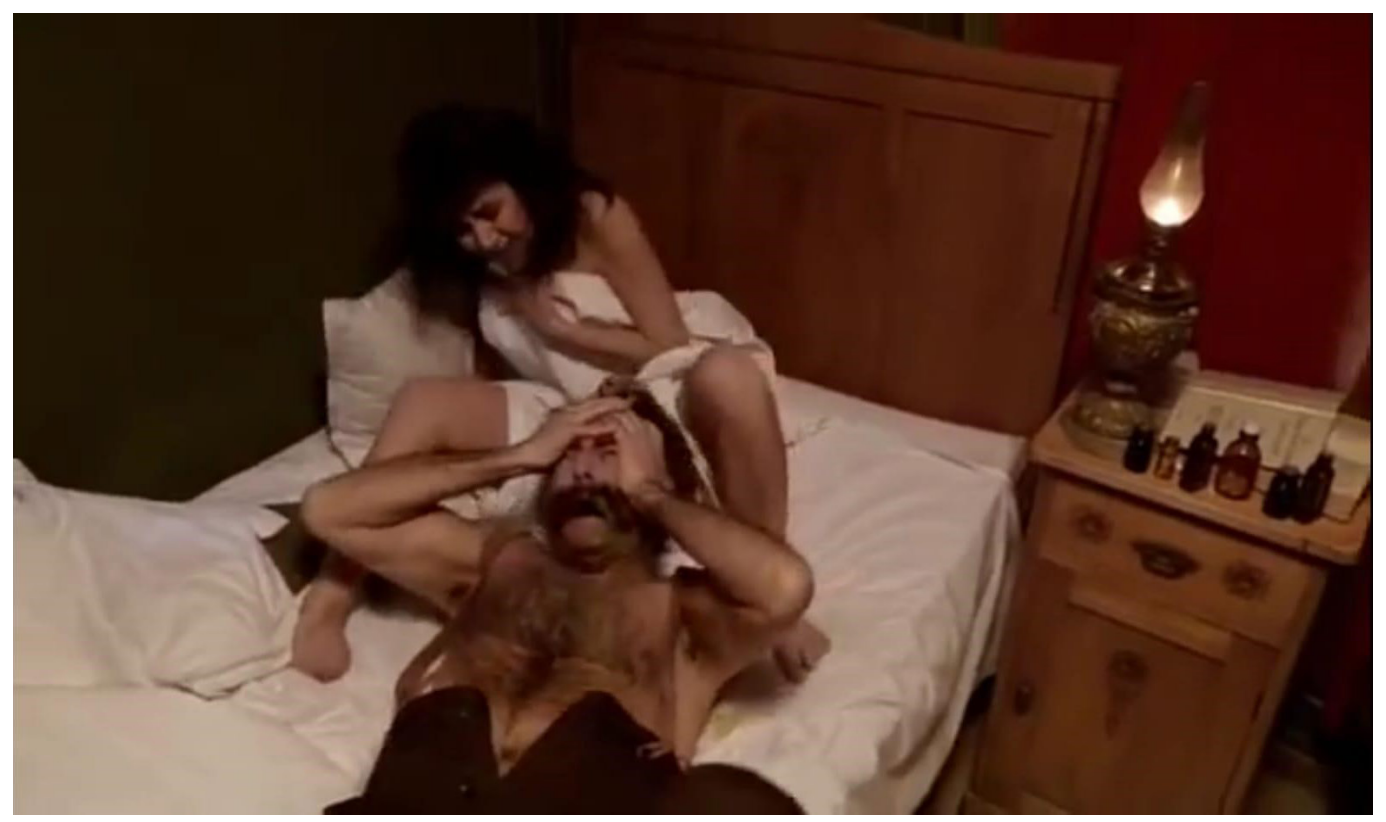

Cefalea intensa. 00:23:13

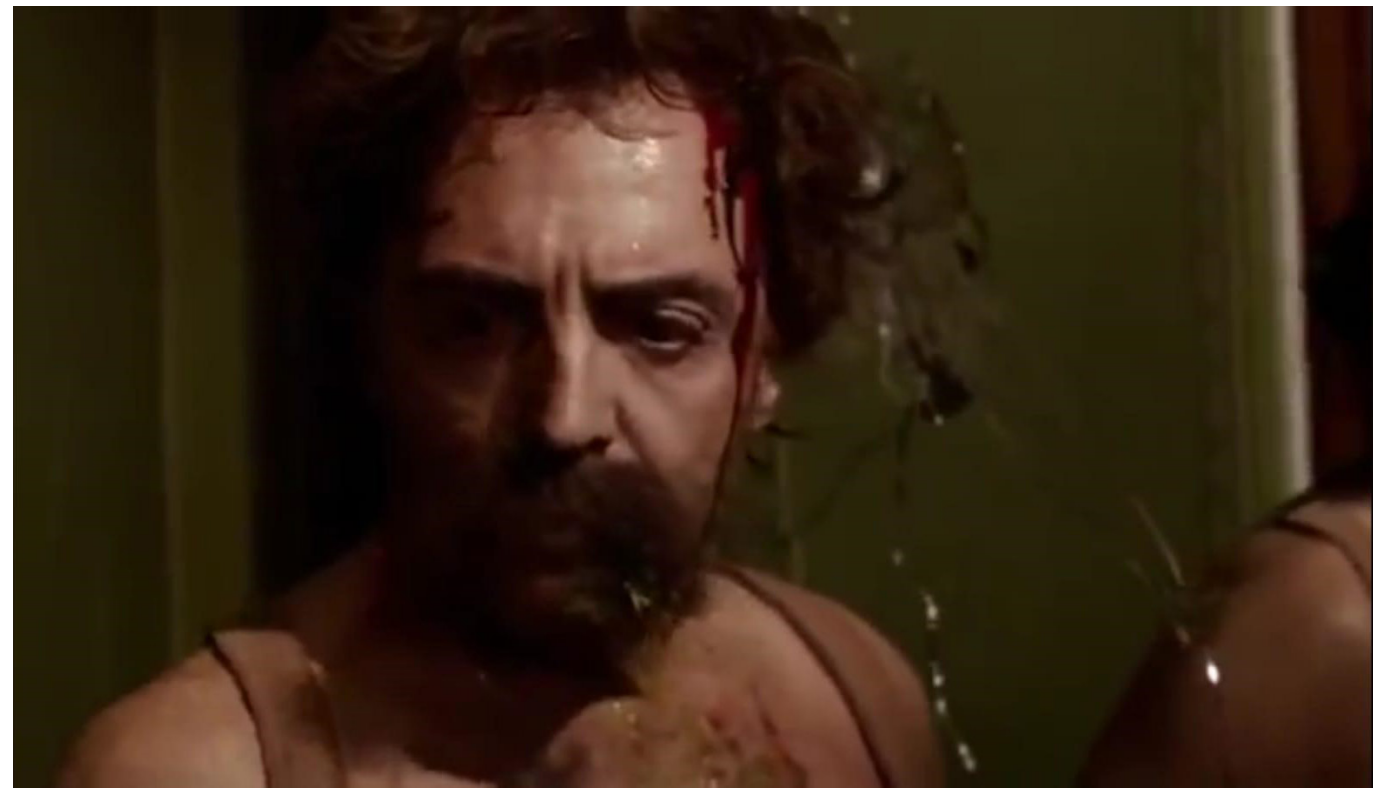

Diaforesis. Se golpea la cabeza violentamente contra el espejo. 00:23:27

Rev. Med. Cine. 2021; 17 (2), 161-169 Ediciones Universidad de Salamanca / ㅇ@

J. Med. Mov., 2021; 17 (2), 161-169 [ 165 ] 
NEUROLOGÍA. EL DÍA QUE NIETZSCHE LLORÓ (2007).

FRIEDRICH NIETZSCHE: UNA APROXIMACIÓN CINEMATOGRÁFICA

SAMANTA PICÓN; IVAN ANDÍA-RODRÍGUEZ

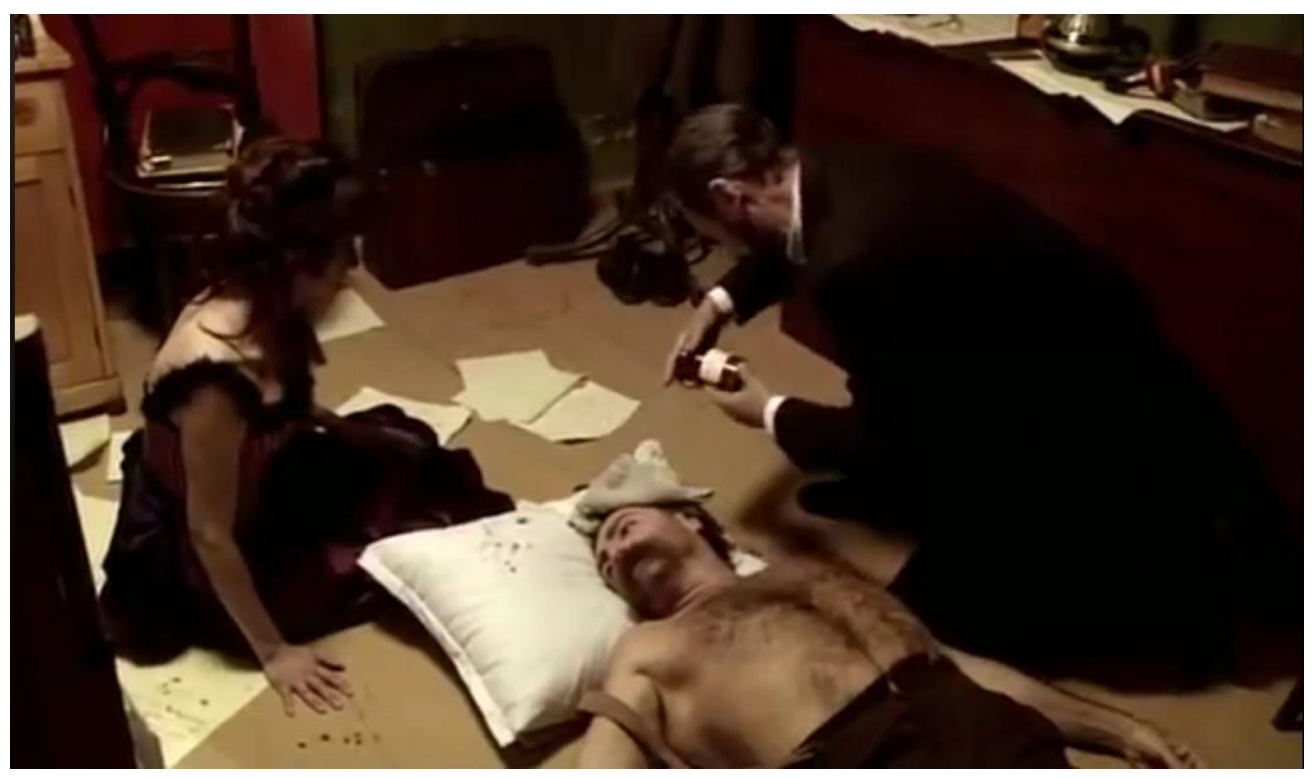

El Dr. Breuer acude en auxilio de Friedrich Nietzsche tras ser avisado por el dueño del hotel. Junto al cuerpo se visualiza un frasco de «cloral» (somnífero). 00:24:15

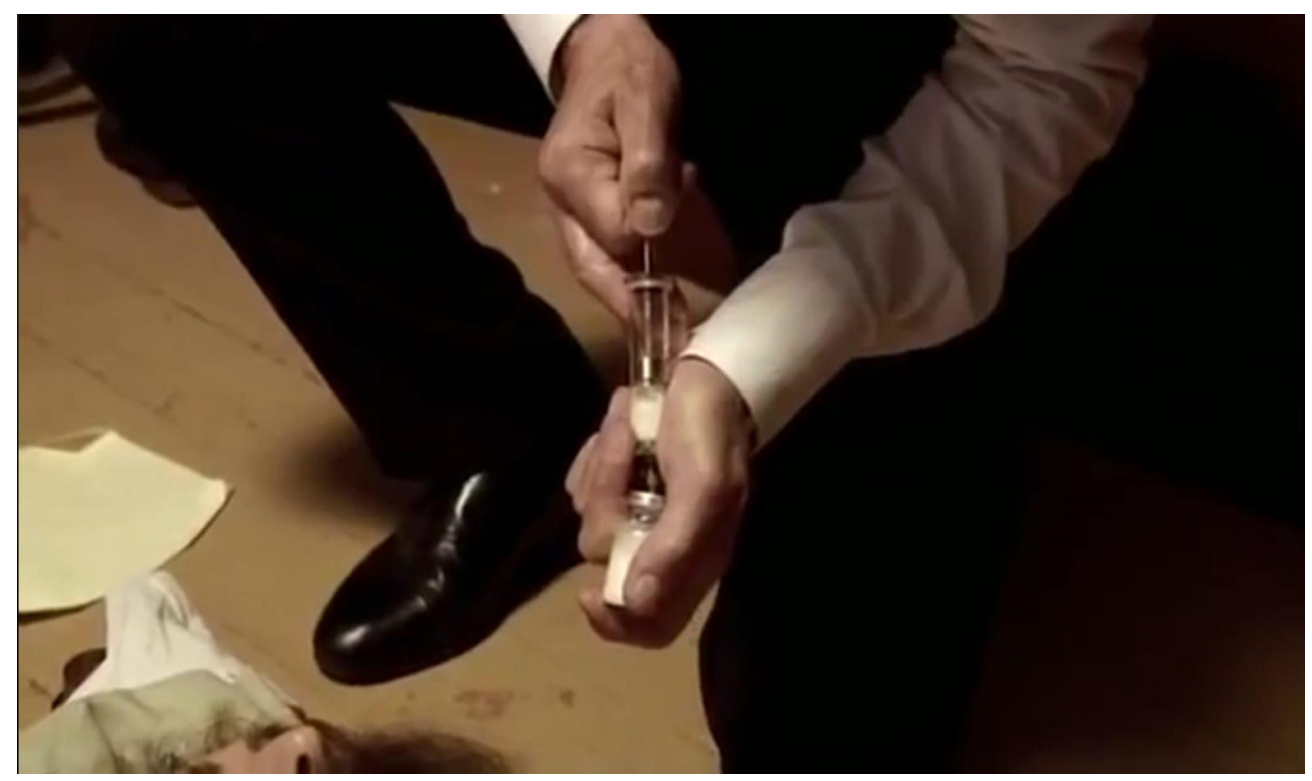

El Dr. Breuer le inyecta una sustancia de aspecto lechoso (sin especificar) en el miembro superior izquierdo. 00:25:05

Rev. Med. Cine. 2021; 17 (2), 161-169 Ediciones Universidad de Salamanca / @®@® J. Med. Mov., 2021; 17 (2), 161-169 [ 166 ] 
NEUROLOGÍA. EL DÍA QUE NIETZSCHE LLORÓ (2007).

FRIEDRICH NIETZSCHE: UNA APROXIMACIÓN CINEMATOGRÁFICA

SAMANTA PICÓN; IVAN ANDÍA-RODRÍGUEZ

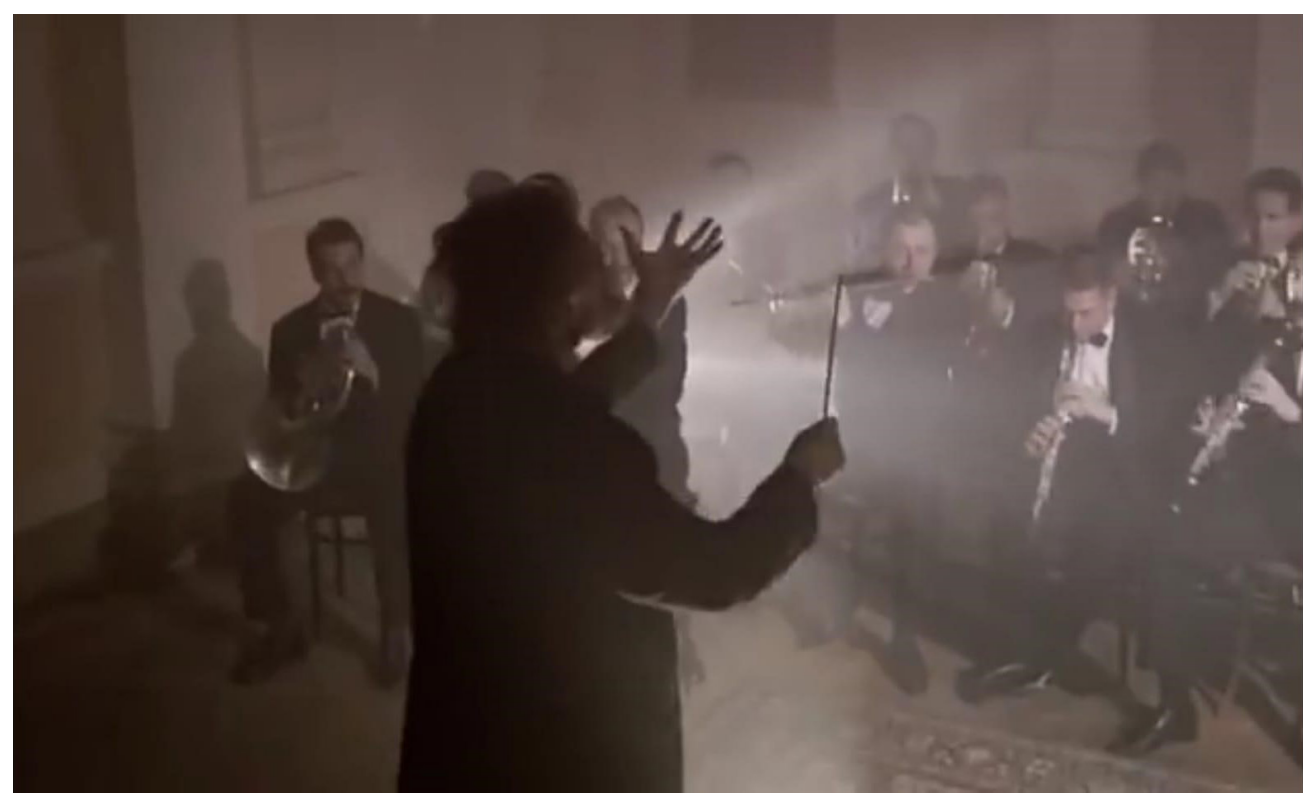

La percepción de la realidad se ve afectada, viéndose envuelto en una alucinación: «Estás enfermo, jestás enfermo!». 01:05:46

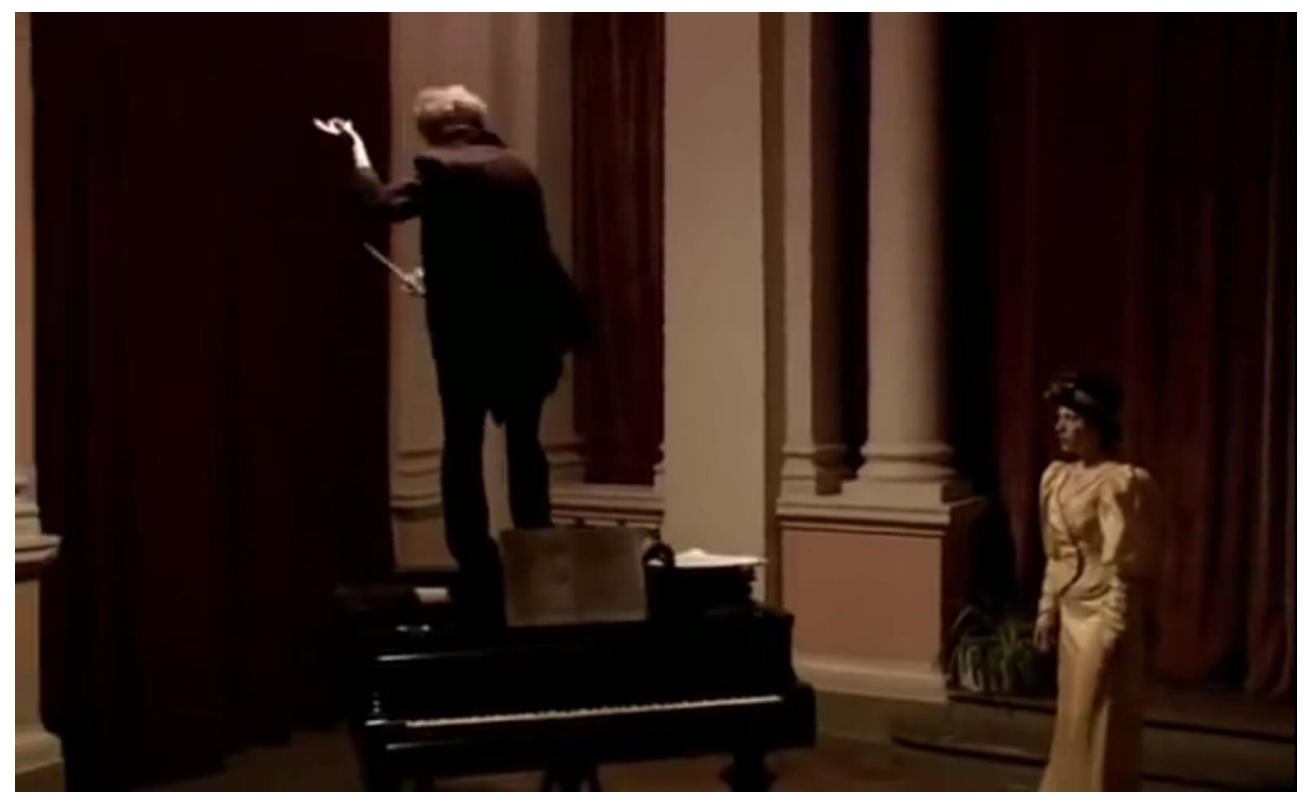

Lou Salome intenta que Nietzsche regrese a la cordura tocando su pierna, sin éxito alguno. 01:07:31

Rev. Med. Cine. 2021; 17 (2), 161-169 Ediciones Universidad de Salamanca /

(9)(9)(9)

J. Med. Mov., 2021; 17 (2), 161-169

[ 167 ] 


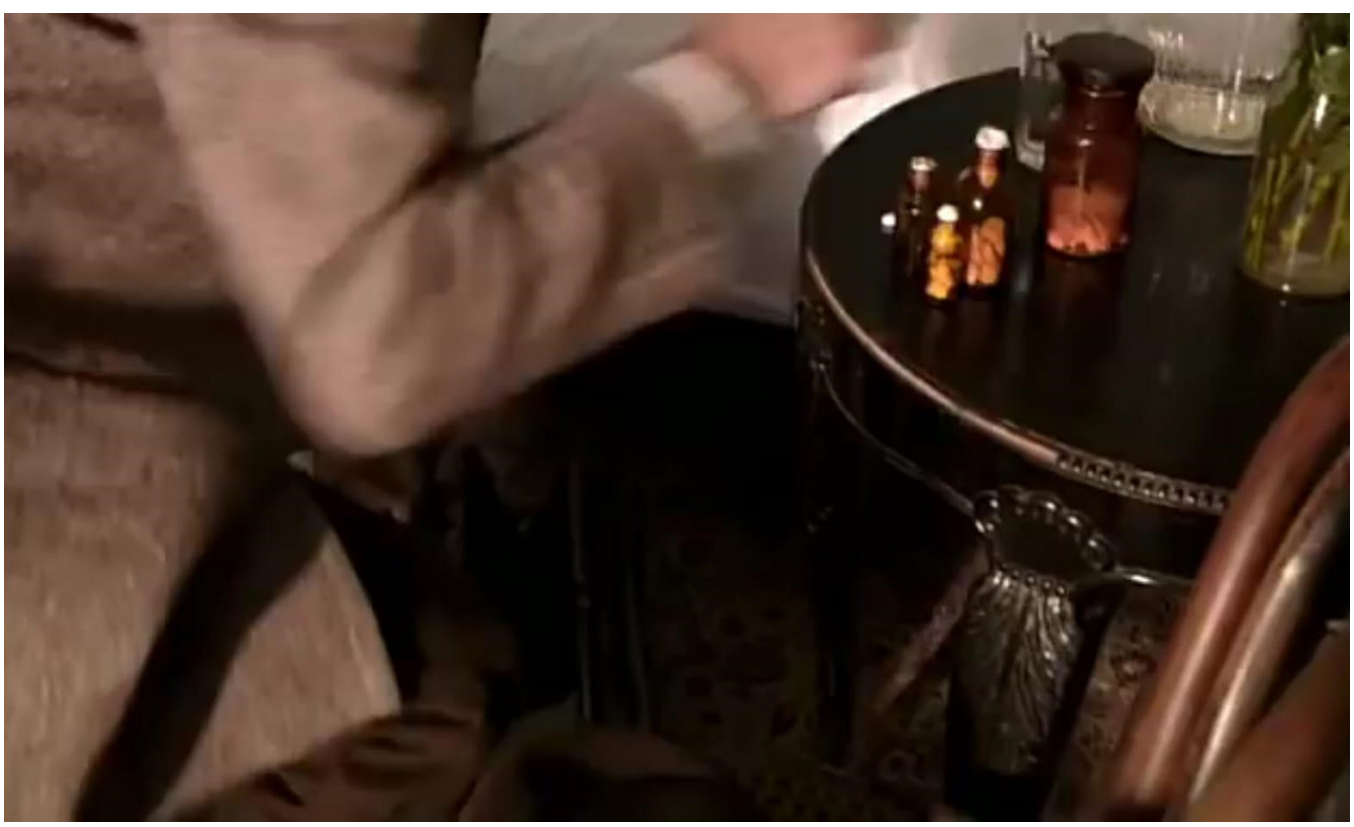

Recoge sus medicamentos y los guarda en su maletín. 01:30:12

"El día en que Nietzsche lloró» presenta a grandes rasgos el padecimiento de Friedrich Wilhelm Nietzsche en su etapa adulta. Al respecto, en la literatura existen diversas hipótesis que no han podido ser corroboradas por falta de métodos diagnósticos no empleados en la época. Se sabe que en el siglo XIX la sífilis fue la etiología más común con inicio subagudo de demencia en los hombres de mediana edad ${ }^{1}$, de esta manera, en los últimos años se ha replanteado el diagnostico que aparece en la película y que fue respaldado por signos y síntomas como: pupilas asimétricas (con una reacción lenta de la pupila derecha a la luz), aparición de ideas extrañas y grandilocuentes, y el desarrollo de demencia ${ }^{1}$. No obstante, a su llegada al asilo en Basilea, las descripciones médicas incumplían con los cinco signos cardinales de neurosífilis de Houston Merritt: las expresiones faciales permanecieron vívidas y evocadoras, los reflejos profundos eran normales, el temblor no estaba presente, la escritura permaneció inalterada, y el habla era fluida (aunque a veces el contenido era extraño) ${ }^{2}$, los rasgos megalomaníacos siempre estuvieron presentes. Por otro lado, en el 2008, Hemelsoet et al. plantean el diagnóstico de "Arteriopatía Cerebral Autosómica Dominante con Infartos Subcorticales y Leucoencefalopatía» (o, por sus siglas en inglés, "CADASIL»), una enfermedad encefálica progresiva de larga data y principal causa genética de ictus; no obstante, esta hipótesis no ha podido ser confirmado debido a la ausencia de diagnósticos por imágenes y dado a que este complejo personaje no tuvo descendientes. CADASIL es el mejor diagnóstico planteado hasta el momento $y$, teóricamente, podría confirmarse con análisis de $A D N$, incluso post mortem (aunque una mutación típica de Notch puede estar ausente en presencia de material osmiofílico granular en varios tejidos) ${ }^{1}$. Finalmente, los signos y síntomas expuestos en el film que defienden este reciente diagnóstico son: ausencia del reflejo patelar derecho (00:12:42),

Rev. Med. Cine. 2021; 17 (2), 161-169 Ediciones Universidad de Salamanca / అ@ J. Med. Mov., 2021; 17 (2), 161-169 
NEUROLOGÍA. EL DÍA QUE NIETZSCHE LLORÓ (2007).

FRIEDRICH NIETZSCHE: UNA APROXIMACIÓN CINEMATOGRÁFICA

SAMANTA PICÓN; IVAN ANDÍA-RODRÍGUEZ

anomalías en la marcha (00:12:56), dolor de cabeza intenso de inicio súbito precedido por cefalea de moderada intensidad (00:23:12), y demencia con agitación y alucinaciones (01:05:48). Asimismo, como antecedente se tiene el comentario de Lou Salome al Dr. Josef Breuer referente a las cefaleas que Friedrich Nietzsche presenta desde los nueve años ${ }^{3}$, describiendolas como «jaquecas que le atormentan»(00:02:30). En relación a un posible trastorno depresivo, se tienen la carta de suicidio enviada por Nietzsche a Lou Salome, y la respuesta de este a la pregunta del Dr. Breuer respecto a su salud: «¿En qué medida la melancolía acompaña esos ataques de migraña?», a lo que Nietzsche responde, «tengo épocas negras, ¿pero quién no?, no tienen importancia. No surgen de mi dolencia, sino de mí.» La conversación sigue con el comentario del doctor Breuer: «Una vida dominada por épocas negras acaba llevando a la desesperación», "Desesperación no. Quizá antes, pero ahora no.» (00:13:23).

\section{Referencias}

1. Hemelsoet D, Hemelsoet K, Devreese D. The neurological illness of Friedrich Nietzsche. Acta Neurol Belg. 2008;108(1):9-16.

2. Gomes Marleide da Mota. Friedrich Nietzsche: the wandering and learned neuropath under Dionisius. Arq. Neuro-Psiquiatr. [Internet]. 2015 Nov [cited 2020 Sep 14] ; 73( 11 ): 972-975.

3. HAYMAN R. Nietzsche : A critical life. New York : Penguin, 1982, 24. 